\title{
Doctor-Patient Relationship in Pharmacological Treatment: Discontinuation and Adherence
}

\author{
Jose Luis Turabian* \\ Specialist in Family and Community Medicine, Spain \\ *Corresponding author: Jose Luis Turabian, Specialist in Family and Community Medicine, Toledo, Spain
}

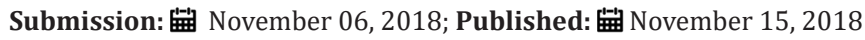

\begin{abstract}
About the doctor-patient relationship has been written quite generally, but nevertheless, there is a lack of analysis on the theoretical and practical concepts regarding the specificity in the therapeutic approach and the discontinuity and pharmacological adherence. By "discontinuity of pharmacological therapy" is meant the interruption of the therapeutic scheme followed by a patient. Many factors influence the doctor-patient relationship in pharmacological treatment, which on the other hand overlap, but the two main factors are the doctor-patient relationship and the complexity/simplicity of the pharmacological treatment. In any case, the discontinuity of the treatment indicates in some way a discontinuity of the doctor-patient relationship. The doctor-patient therapeutic relationship is the environment where the rest of the therapeutic instruments, pharmacological or not, is housed. Each type of doctor-patient relationship implies a different relationship with pharmacological treatment; but also, the doctor-drug approach style imposes a doctor-patient relationship. This article reflects on:
\end{abstract}

1) Doctor himself as a drug;

2) The context that the doctor creates is itself also a drug;

3) The fact of prescribing pharmacological treatments changes the patient's thoughts, emotions and behaviors;

4) The complexity/simplicity of the pharmacological regimen;

5) The special doctor-patient relationship in the repeated prescriptions;

6) The doctor-family relationship and companions and caregivers in pharmacological treatment;

7) The characteristics of the patients; and

8) The types and phases of diseases.

Keywords: Physician-patient communication; Adherence; Pharmaceutical treatment; Therapeutic alliance; Inappropriate prescribing, General practice; Framework; Decision making; Therapeutic adherence; Physician-patient relations; Sanitary attention

\section{Introduction}

For the World Health Organization, therapeutic adherence is defined as the degree to which the behavior of a person corresponds with the accepted recommendations of the health professional [1]. Probably, around $40-50 \%$ of the patients do not take the prescribed drugs in an adequate way (as, for example, they occur in treatment due to hypertension or bronchial asthma) [2]. And this figure is considerably higher even in the developing countries [3].

However, non-adherence behaviors encompass a wide range of possibilities, ranging from irregular taking of drugs and short periods of rejection of medicines to premature abandonment of treatment [4]. On the other hand, the poor adherence to treatment can take various forms: difficulties to initiate it, premature suspension or abandonment, incomplete or insufficient compliance with the indications, which can be manifested as errors of omission, dose, time, purpose (mistake in the use of one or another medicine), the absence of consultations on the day indicated and at the agreed time, the absence of modification of habits and lifestyles necessary for the improvement of the disease, the practice of self-medication or taking medicines when remember or only until you run out of the box or the blister [5].

Therefore it seems preferable to speak of "discontinuity of pharmacological therapy", which is understood by the interruption of the therapeutic scheme followed by a patient, which may have been established by the doctor (discontinuation or switching), by the clinical basis (presence of adverse reactions to the drug, persistence of symptoms, or improvement that eventually requires discontinuing or changing drugs), or performed autonomously by the patient [2].

The pharmacological prescription is a fundamental element in the medical consultation. Four ways of interpreting the role of medications in medical services can be considered: 
a) as tools to modify the natural course of a disease, prevent an illness or make a diagnosis;

b) as a way to measure medical behavior;

c) as indicators to measure the results of the impact that their use causes in the community; and

d) as an element in the doctor-patient relationship. This last level of studying pharmacological prescription is very little used, despite the fact that the doctor-patient relationship is the intervention that the doctor most frequently uses in his relationship with the patient [6].

Thus, adherence to treatment and pharmacological discontinuity are inscribed in the first place in the doctor-patient encounter, and the qualities of this relationship influence one way or the other. A general view of the therapeutic continuity in general and the pharmacological continuity in particular can show us several factors: the prescription, the doctor's objectives, the health problem/the pathology, the meaning of the environment, the informed consent, the socio-economic condition, subjective well-being, the patient's objectives, the perception of the disease, family support, the evolution or course of the disease, the duration of treatment, the doses, the transference and countertransference phenomenon, the placebo effect and nocebo , the non-pharmacological effects of the medications, the adverse reactions to the drug, the quality of life, etc. [2,7-9]. It is important to bear in mind that it is not possible to separate the instrumental treatment, such as the medication and other biological interventions, from the effect in the treatment of the doctor-patient relationship [10].

In this scenario, about the subject of doctor-patient relationship has been written quite generally, but nevertheless, there is a lack of analysis on the theoretical and practical concepts regarding its specificity in the therapeutic approach and the discontinuity and pharmacological adherence [5]. On the other hand, this analysis acquires relevant peculiarities in the current health care, and possibly with greater repercussion in the consultations of general medicine, which is the level of care where the majority of own or referred prescriptions (pharmacological prescriptions of hospital care) are performed [11].

\section{Discussion}

The discontinuity of the treatment indicates in some way a discontinuity of the doctor-patient relationship. The doctor-patient therapeutic relationship is the environment where the rest of the therapeutic instruments are housed, pharmacological or not [12]. (Table 1) shows a panoramic view of the factors of the doctor-patient relationship that are related to the adherence or discontinuity of pharmacological treatment $[13,14]$. Of all these factors -which, on the other hand, overlap-, the two main factors in the discontinuity and pharmacological adherence are the doctor-patient relationship and the complexity/ simplicity of the pharmacological treatment [15].

Table 1: Factors of doctor-patient relationship in pharmacological treatment, the discontinuation and adherence.

\begin{tabular}{|c|c|}
\hline $\begin{array}{c}\text { Factors of Doctor-Patient Relationship in Pharmaco- } \\
\text { logical Treatment }\end{array}$ & Concepts \\
\hline \multirow{3}{*}{ From doctor } & $\begin{array}{l}\text { According to the relationship model "context creator" (informative, persuasive, participato- } \\
\text { ry-cooperative-empowerment) }\end{array}$ \\
\hline & $\begin{array}{l}\text { According to types of doctor-patient relationship (active-passive, guided cooperation, mutu- } \\
\text { al participation) }\end{array}$ \\
\hline & $\begin{array}{l}\text { The fact of prescribing pharmacological treatments changes the patient's thoughts, emotions } \\
\text { and behaviours, mediated by the non-chemical psychosocial effects, but additive to the phar- } \\
\text { macological effects, and consequently modifies the doctor-patient relationship, and so, can } \\
\text { be very difficult the interventions by educational councils or by different psychotherapies }\end{array}$ \\
\hline \multirow{4}{*}{ From patients } & -Safe, worried, fearful, independent patients, etc. \\
\hline & -Patient competitors with the doctor or doctor's dependents \\
\hline & $\begin{array}{l}\text {-Emotional characteristics and personality traits that predict pharmacological discontinuity: } \\
\text { people who perceive situations as dangerous or threatening, cautious people, tenses, easily } \\
\text { fatigable, timid, apprehensive, pessimistic, etc., or if the patient is a person with depressive } \\
\text { personality (individuals that are characterized by particularly serious, unable to have fun or } \\
\text { relax and humourless, with negative thoughts, pessimistic, etc., even without there being an } \\
\text { identifiable mental illness such as anxiety and / or depression) }\end{array}$ \\
\hline & According to ages (child, adult, elderly) \\
\hline From companions or family & $\begin{array}{l}\text { Relationship doctor-family and companions or caregivers that implies an aid or a barrier } \\
\text { regarding the pharmacological compliance of the patient }\end{array}$ \\
\hline \multirow{7}{*}{ Factors from the disease } & Disease factors that modulate doctor-patient relationship in pharmacological treatment: \\
\hline & Beginning: acute / gradual \\
\hline & Course: progressive, constant, recurrent \\
\hline & Result: non-fatal, limiting life expectancy, fatal. \\
\hline & Inability: no disability, moderate, severe \\
\hline & Grade of uncertainty or predictability. \\
\hline & Other factors: Visibility of symptoms; Severity of crises; Genetic contribution \\
\hline
\end{tabular}




\begin{tabular}{|c|c|}
\hline \multirow{5}{*}{ Factors of the drug } & $\begin{array}{l}\text { Factors of the therapeutic regimen that influence doctor-patient relationship in pharmaco- } \\
\text { logical treatment: }\end{array}$ \\
\hline & $\begin{array}{l}\text { Polypharmacy and complex regimens do not facilitate adherence. The average number } \\
\text { of medications taken by patients when they fail their pharmacological treatment is } 5.5 \\
\text { medications, there being no group of drugs more directly involved, and it is an eventuality } \\
\text { that can reach any type of medication. Although, antihypertensive drugs are the group most } \\
\text { consumed by the population, and in turn, one of the most affected in terms of adherence to } \\
\text { pharmacological treatment }\end{array}$ \\
\hline & Adverse reactions \\
\hline & $\begin{array}{l}\text { The heterogeneity of presentation of the same drug according to the laboratory that produc- } \\
\text { es it (generics ...) }\end{array}$ \\
\hline & The repeated prescriptions \\
\hline \multirow{4}{*}{$\begin{array}{l}\text { Factors associated with continuity of care in general } \\
\text { medicine }\end{array}$} & $\begin{array}{l}\text { Factors associated with continuity of care which influence doctor-patient relationship in } \\
\text { pharmacological treatment: }\end{array}$ \\
\hline & $\begin{array}{l}\text { The presence of multiple adverse drug reactions in a patient in general medicine is indica- } \\
\text { tive of anxiety-depression, and constitutes a signal of potential psychosocial problems in the } \\
\text { patient context }\end{array}$ \\
\hline & $\begin{array}{l}\text { Moment of discontinuity: the factors that govern early therapeutic adherence are possibly } \\
\text { different from those that govern adherence in the maintenance phase }\end{array}$ \\
\hline & $\begin{array}{l}\text { The long-term therapeutic adherence gradually decreases as the improved patients con- } \\
\text { clude that they no longer need the medication or have less tolerance for some previously ac- } \\
\text { ceptable effects such as secondary sexual effects. They may also develop fear thinking about } \\
\text { the onset of long-term adverse effects or cumulative effects of addiction or chronic toxicity }\end{array}$ \\
\hline \multirow{3}{*}{ Factors of the health system } & $\begin{array}{l}\text { Factors associated with sanitary system which influence doctor-patient relationship in } \\
\text { pharmacological treatment: }\end{array}$ \\
\hline & $\begin{array}{l}\text { The process of "induced prescription" (prescription from another doctor, usually a hospital } \\
\text { consultant) results in an alteration of the doctor-patient relationship }\end{array}$ \\
\hline & Currently prescriptions are repeated using computer or electronic means \\
\hline
\end{tabular}

\section{Doctor-patient relationship: The doctor himself as a} drug

The doctor-patient relationship is fundamental both for the diagnosis and for the treatment. All health care activity is influenced, directly or indirectly, by the interpersonal relationship. Communication allows the integration of clinical reasoning by connecting the biomedical and psychosocial aspects of clinical care. The interview is a technique or a channel and place of communication, where the patient-doctor relationship is produced and developed. The doctor's relationship with the patient is the true core of clinical practice in general medicine [16].

For Balint, the drug most used in general practice is the doctor himself; the interview itself is therapeutic. In his writings on "the doctor as a medicine" he establishes the fact that himself as a drug can be dosed, prescribed, and is able to produce intoxication like any drug. Relatively often the relationship between the doctor and the patient is poor or tense; in these cases, the "medication" does not achieve the expected results. This medicine called "doctor" is powerful and can have many side effects. You have to know how to dose and prescribe [17]. In any case, it is accepted unanimously that the chances of success in a treatment are directly proportional to the quality of the doctor-patient relationship [18].

In the professional interaction patient-physician, the existence of an effective communication and the satisfaction of the patient with this relationship take on considerable importance. It has been observed that providing the necessary information in a way that favors and guarantees minimum levels of understanding on the part of the patient contributes to improving adherence. Similarly, the satisfaction of the patient, from the affective point of view, with the relationship established with the therapist has been associated with a marked increase in therapeutic compliance. Thus, this aspect highlights the importance of the medical-patient therapeutic alliance, which in the initial instance will constitute the first element of fortification of the patient's compliance with the medical recommendation and by both will have a considerable influence on the therapeutic process and in the final results of treatment. Without an adequate alliance from the beginning of therapy, adherence is less likely to subsist $[2-4,10]$.

This importance attributed to the therapeutic alliance highlights the relevance of the relational dimension between therapist and patient. The patient and the doctor should interact, discuss and decide on whether to perform pharmacological treatment, when and how; This interaction and the discussion on the subjects of uncertainties, concerns and possible adverse reactions, allows to improve adherence to the drug [10]. Attentive listening, the demonstration of sincere interest in helping the patient and the affable treatment allows the therapist to place himself in a position next to the patient, and in this way demonstrate in a manifest way his interest in taking up with the patient the confrontation of his health problems [5].

This active listening allows the doctor to elaborate the biopsycho-social meaning of the symptom, that is, the elaboration of a kind of cartography or map of the patient, and of the doctor: the symptom as seen by the doctor and the prognosis of evolution 
of this symptom, and on the other hand, the perception of the patient with what he feels and thinks has changed in his life by this symptom, as well as his forecast of what will happen next, his defense mechanisms, the structure of his personality, his sociolabor and familiar situation, his idea of pharmacological treatment, his motivation, his expectation of the result, of the adverse effects, the participation of caregivers or relatives, and the anticipation of change of the sentinel symptom with respect to the efficacy of the drug $[8,18]$.

The pharmacological prescription is the end of the consultation, after the elaboration of this map of the patient, and of the diagnosis. In this way, we can realize that the doctor and the prescribed drug are united - stuck together-, so the therapeutic alliance is an alliance of the patient with the doctor where the prescribed drug is included. In any case, it is necessary to take into account that the doctor should not fall into a paternalistic attitude, nor make the patient a dependent being. Both attitudes are counterproductive. (Table 2) presents three types of doctor-patient relationship that are frequently used with the patient, where the pharmacological prescription is inserted. Each type of doctor-patient relationship implies a different relation or typology of participation with the pharmacological treatment; but also, the medical-drug union style (as the doctor understands or interprets the meanings and importance of the drug in its way of making medicine) imposes a doctor-patient relationship (Figure 1) [19-23].

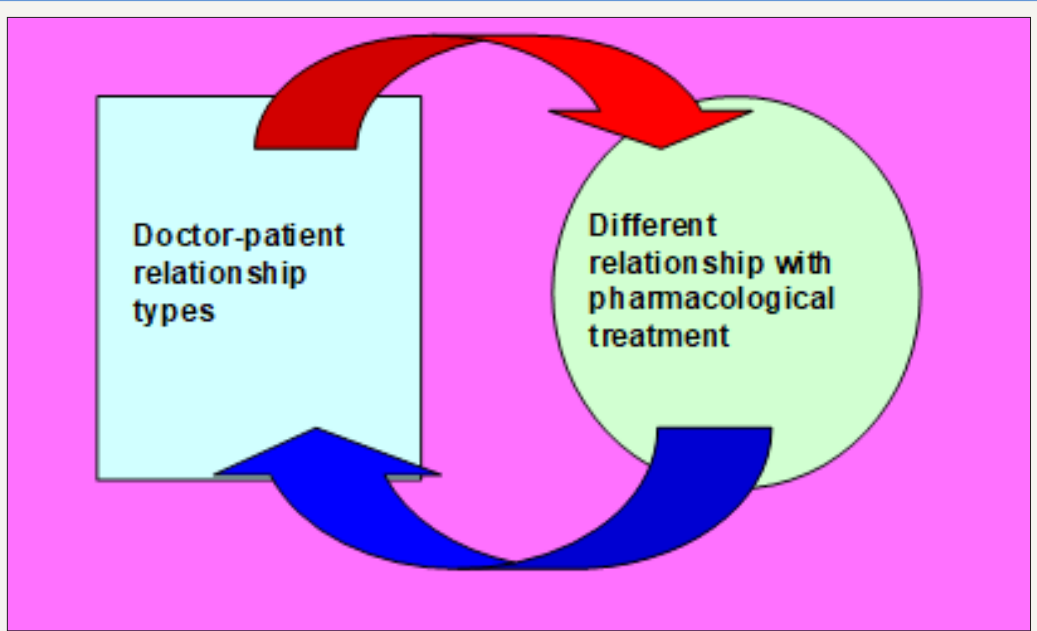

Figure 1: Each type of doctor-patient relationship implies a different relationship with pharmacological treatment; but also, the doctor-drug union style imposes a doctor-patient relationship.

Table 2: Three types of doctor-patient relationship that are frequently used with the patient.

\begin{tabular}{|c|c|}
\hline Types of Doctor-Patient Relationship & Concept \\
\hline "Active-passive" relationship & $\begin{array}{c}\text { Patient participates very little in the relationship. Doctor behaves with the patient as a fa- } \\
\text { ther would with his child of a few months of age. The doctor totally manages the situation. } \\
\text { It may be adequate in the acute stages }\end{array}$ \\
\hline "Guided cooperation" relationship & $\begin{array}{c}\text { Patient can receive orientations and cooperate in its treatment. Doctor behaves like a } \\
\text { father in front of a teenage son. It pursues ties that guarantee the accomplishment of the } \\
\text { appropriate treatment. It may be adequate after the acute phase of the diseases }\end{array}$ \\
\hline "Mutual participation" relationship & $\begin{array}{c}\text { Doctor should discuss with the patient his management of the disease and anxiety-creat- } \\
\text { ing situations. It may be adequate in the chronic phase }\end{array}$ \\
\hline
\end{tabular}

\section{The context that creates the doctor is in itself also a drug}

Table 3: Three models of relationship "creators of context".

\begin{tabular}{|c|c|}
\hline & Concept \\
\hline $\begin{array}{l}\text { 1.-Unidirectional } \\
\text { information strategy }\end{array}$ & $\begin{array}{l}\text { Relationship between doctor and patient is "dissociated": the needs of both may be different and are not taken into account. } \\
\text { Relations centered on the doctor and what he believes should be done ("decontextualized" model). }\end{array}$ \\
\hline $\begin{array}{l}\text { 2. Persuasive or con- } \\
\text { sultative strategy }\end{array}$ & $\begin{array}{l}\text { Relationship between doctor and patient is "convergent": it shows interest or concern for the other or adjusts to the other. It } \\
\text { can includes the following tools during the relationship: } \\
\text {-Marketing oriented to the patient and promoting the service (presenting it as interesting and relevant to their needs) } \\
\text {-Persuading, motivating } \\
\text {-Negotiating (making the agenda and arranging the content to the particular patient, together with "activities" that the doctor } \\
\text { considers indispensable ...) } \\
\text { - "Social marketing" (the use of marketing practices for social purposes) }\end{array}$ \\
\hline
\end{tabular}


3.-Participatory strategy-cooperative with empowerment
Relationship between doctor and patient is "sharing" and "help" (contextualized). It implies a model where there is a therapeutic relationship between doctor and patient in which there is a genuine effort to grant faculties to patients based on the relationships between them and their contexts.
Doctor-patient relationship model is a "contextcreator" element through the relationships and communications established with the patients in the consultation. The "creation of context" is the result of implementing a series of doctor-patient relationship strategies to make services acceptable, relevant and accessible. (Table 3) shows three relationship models "context creators". The models of doctor-patient relationship are superimposable to the educational models and to the types of participation (Table 2). These models are not mutually exclusive and may overlap.

In each type of doctor-patient relationship different conditions of the educational association can be observed. Within these relationship models, the significant-participatory-cooperativetrainer strategy is especially important, where the relationship between doctor and patient is "sharing" and "helping" and implies a therapeutic relationship between doctor and patient [16,24]. It's important to put attention that this therapeutic context induces biomedical processes in the patient's brain that may enhance or reduce the effects of chosen interventions. The context thus works as a drug, with real effects and side effects $[9,25]$. It must be remembered that, the nocebo-placebo effect is also included here $[26,27]$

\section{The fact of prescribing pharmacological treatments by doctor modifies the doctor-patient relationship}

The fact of taking drugs (especially some of them as psychotropic drugs, and chronically repeated drugs, etc.) modifies the results of the educational council or the different psychotherapies; in other words: they can make the results of counselling and psychotherapies very difficult, due to the changes of thought, emotions and behaviors, mediated by the non-chemical pso-social effects, but additives to the pharmacological effects, which produce the drugs [28].

Thus, when doctor prescribes one or more drugs, he must be aware that he must modify his doctor-patient relationship so that the "psychotherapy" or advice that occurs within the psychosocial effect of the doctor-patient relationship is adequate and useful. The drugs can make the effect of the "doctor himself as a drug" is more difficult, favour a relational context that is not significant neither for the doctor nor for the patient, where the doctor does not delve into the true meaning of the patient symptoms, and the patient tends not to get involved, to make an emotional withdrawal, to be passive in front of the fact of the prescribed drug [28].

\section{The complexity/simplicity of pharmacological thera- peutic regimen}

Taking several medications simultaneously makes it harder to remember when to take each one and increases the risk of adverse interactions between drugs. To improve compliance and reduce the risk of interactions, the doctor can simplify the drug regimen by using a drug that serves two purposes, or by reducing the number of times the medication should be taken. Because older people are generally more sensitive to drugs than young people, they are much more likely to have adverse reactions and need a lower dose of certain drugs. It is admitted that, on average, a quarter of an hour after the consultation with the doctor, patients have forgotten about half of the information that the doctor has given them. They remember better the first third of the conversation and are more aware of the diagnosis than the details of the treatment. This is the reason why doctors should try to establish a simple therapeutic plan and give written instructions.

As an alternative to the complexity of the pharmacological regimen, the polypill has been proposed, a combination of a statin, aspirin, drugs to lower blood pressure, and folic acid [29,30]. Although this strategy tends to favour the disappearance of the "doctor himself as a drug" to appear the "doctor as drug dealer": in this alternative virtually disappear the doctor and is established a "drug-patient" relationship [31].

\section{The special doctor-patient relationship in the repeated prescriptions scenario}

The repeat prescriptions are a frequent procedure in general medicine to proceed to solve certain needs of patients through repeated prescriptions of drugs during certain time: a medication that once prescribed is continued over a period of time, sometimes for years, or for life (for example, antihypertensive, antidiabetic, anticoagulants, statins, bronchodilators, antidepressants, acetylsalicylic acid, etc.). These patients tend to consult in general more frequently than the rest of patients, tend to have multimorbidity and polypharmacy, accept the drug as a symbol of something, and demand it as a right. Any change in drugs, dose modification or withdrawal is experienced by patient in a problematic way.

Repeated prescription represents "a second-best resolution of the problem" for both the patient and the physician. It is a "peaceful and hopeless struggle" in which both doctor and patient are defeated. Therefore, it implies therapeutics of disappointment, frustrated love, unfulfilled achievement or unresolved fears. Somehow, in spite of all the understanding, in the prescriptions repeated over the years, an icy paralysis clings to the doctor-patient relationship. But also, the situation of repeated prescription includes the sense that this medication was not entirely unsuccessful; in the "peaceful repetitions" of the drug, in some way life becomes tolerable and conflicts remain latent. The study of the situation of repeated prescriptions may reveal that the world of the doctor seems irrational and not scientific at first, and the patient's world appears extremely heavy and human. Thus, "patients with repeated prescriptions" constitute an identifiable group of special characteristics, and the doses of the "drug"-doctor (the doctor himself as a drug) tend to be lower than in the rest of the consultations. Thus, it would be better to say that the special characteristics are not so much of the patients, nor of the doctor, but of the doctor-patient relationship, and this can be a scenario of some difficulty for the doctor [17]. 
It has to bear in mind that the mechanisms that govern early therapeutic adherence are possibly different from those that govern adherence in the maintenance phase. In this last phase, patients are less depressed than in the acute phase and therefore their perceptions may be less negative. In contrast, early withdrawal from medications is related to their side effects and the perception that the medication is not effective. These factors may not have an influence on patients who maintain the continuous use of the antidepressant whose adverse effects have disappeared or who have a favorable therapeutic response. So, the long-term therapeutic adherence gradually decreases as the improved patients conclude that they no longer need the medication or have less tolerance for some previously acceptable effects such as secondary sexual effects. They may also develop fear thinking about the onset of long-term adverse effects or cumulative effects of addiction or chronic toxicity [5,32].

\section{The doctor-family and companions and caregiver's rela- tionship}

Another factor of relevance in the doctor-patient relationship and continuity/pharmacological discontinuity is the support of the family to help compliance with the treatment. The physicianpatient relationship is part of the patient's larger social system and is influenced by the patient's family. Many consultations occur on a single patient, but other times involve patient's family or companions' or caregivers in the medical office. A patient's family member can be a valuable source of health information and can collaborate in making an accurate diagnosis and planning a treatment strategy during the visit to the office. A second adultusually parents or husband/wife accompanying the patient's consultation is always significant and deserves the doctor's attention $[33,34]$. If to this is added that sometimes the patient with a certain disorder conceals symptoms for fear of reproach or feeling stigmatized, social and family support acquires transcendental dimensions [8].

\section{Patients characteristics (emotional, personality traits, age)}

Patients treated in general medicine can have very diverse characteristics: Safe, worried, fearful, independent patients; Patient competitors with the doctor and dependents of the doctor. In any case, the patients have emotional characteristics and personality traits, whose knowledge may allow identifying which of them, will have a placebo response and which of them a nocebo response in relation to the prescription drug. Family doctor should know the characteristics of their patients to maximize the placebo effect and minimize the nocebo and investigate the emotional and contextual problems in cases of patients with nocebo effects [7].

The age of the patient influences the establishment of the doctorpatient relationship in pharmacological treatment, discontinuity and adherence. Children have a lower disposition than adults to take or receive drugs according to the indications. It is not usually easy to get children to take drugs that have a bad taste, that impress or frighten, or that are administered by injection. Regarding older patients, although it is likely that old age by itself does not affect compliance, this is influenced by physical or mental deterioration, polypharmacy and increased risk of drug interactions and side effects.

\section{Types and phases of diseases}

The medical-patient relationship can be different according to the psychosocial aspects of diseases. It is admitted that the doctor-patient relationship in pharmacological treatment can be especially complex in mental health problems, but the different biopsychosocial typologies of the diseases allow different classifications, which produce different repercussions in the doctorpatient relationship in pharmacological treatment (Table 1). With these variables a relationship matrix can be constructed. However, there are some diseases that can be located in different places, and these cannot be placed with some certainty in that matrix (Table 4).

Table 4: Approach to a matrix of the natural psychosocial history of diseases which may imply modifications of doctorpatient relationship in pharmacological treatment.

\begin{tabular}{|c|c|c|c|c|c|}
\hline \multirow{2}{*}{\multicolumn{2}{|c|}{ Acute }} & \multicolumn{2}{|r|}{ Incapacitant } & \multicolumn{2}{|c|}{ Not Disabled } \\
\hline & & Gradual & Acute & Gradual & \\
\hline \multirow{2}{*}{ Fatal } & Progressive & Acute leucemia & $\begin{array}{l}\text { Lung cancer } \\
\text { Heart failure }\end{array}$ & $\begin{array}{c}\text { Traffic accident } \\
\text { PE }\end{array}$ & Cystic fibrosis \\
\hline & Recurrent & $\begin{array}{l}\text { Incurable cancer in } \\
\text { remission }\end{array}$ & $\begin{array}{c}\text { General multiorganic fragility of the } \\
\text { elderly }\end{array}$ & Adverse Drug Reaction & Suicide attempt \\
\hline \multirow{3}{*}{$\begin{array}{l}\text { Limited } \\
\text { Expectation } \\
\text { of Life }\end{array}$} & Progressive & Myasthenia gravis & $\begin{array}{c}\text { COPD } \\
\text { Multiple sclerosis }\end{array}$ & $\begin{array}{c}\text { Prostate cancer } \\
\text { thromboangiitis oblit- } \\
\text { erans }\end{array}$ & $\begin{array}{c}\text { Diabetes mellitus } 1 \\
\text { and } 2\end{array}$ \\
\hline & Recurrent & Coronary & Angina pectoris & Hemophilia & SLE \\
\hline & Constant & $\begin{array}{l}\text { Cerebrovascular } \\
\text { accident }\end{array}$ & $\begin{array}{l}\text { Chronic Renal Failure } \\
\text { Hodking disease }\end{array}$ & Hyperthyroidism & Drug's use \\
\hline
\end{tabular}




\begin{tabular}{|c|c|c|c|c|c|}
\hline \multirow{3}{*}{ No fatal } & Progressive & Schizophrenia & $\begin{array}{c}\text { Parkinson's disease } \\
\text { Arthrosis }\end{array}$ & Nephrolithiasis & $\begin{array}{l}\text { Hypertension } \\
\text { Osteoporosis }\end{array}$ \\
\hline & Recurrent & Hernia disc & $\begin{array}{l}\text { Depression } \\
\text { Anxiety }\end{array}$ & $\begin{array}{c}\text { Gout } \\
\text { Migraine } \\
\text { Epilepsy } \\
\text { Asthma } \\
\text { Seasonal allergy }\end{array}$ & $\begin{array}{l}\text { Ulcerative colitis } \\
\text { Irritable colon } \\
\text { Psoriasis }\end{array}$ \\
\hline & Constant & $\begin{array}{l}\text { Cerebral palsy } \\
\text { Total deafness }\end{array}$ & Congenital malformations & $\begin{array}{c}\text { Congenital heart disease } \\
\text { Gallstones }\end{array}$ & $\begin{array}{l}\text { Hypertension } \\
\text { Glaucoma } \\
\text { Distimia } \\
\text { Dental caries }\end{array}$ \\
\hline
\end{tabular}

PE: Pulmonary Embolism

\section{COPD: Chronic Obstructive Pulmonary Disease}

\section{SLE: Systemic Lupus Erythematosus}

It must be borne in mind that the general beliefs about the medications that the patient may have behave differently, whether the patient's illness is in the acute or maintenance phase; so, it is estimated that they may be more relevant in the acute phase. During the start of the treatment, the subjects form a cognitive representation of whether medications are needed and if they will cause problems. Drugs can be seen as toxic, as unnatural "chemical" products that make the body sick, etc. Another sociocultural consequence is the distortions on drugs that appear with sensationalism in the mass media. Often, medicines are judged by the side effects or interaction of medications and inadequate information can become a boomerang that returns with noncompliance or generates a certain state of fear and even panic. The consequence for the doctor is that taking medications has many meanings and sometimes deciding which one has great influence on the patient is an art to find out [8].

\section{Conclusion}

Having an adequate knowledge of the phenomenon of adherence to treatment is to be able to address it effectively in order to make the improvement of the patient becomes evident and does not run the risk of deriving a true or pseudo-chronicity or in a pseudo-resistance pharmacological or recurrences occur due to failure to achieve adequate compliance.

Many factors influence the doctor-patient relationship in pharmacological treatment, which on the other hand overlap, but the two main factors are the doctor-patient relationship and the complexity/simplicity of the pharmacological treatment. The interaction between patient and doctor is fundamental for the prescription process of drugs. An adequate therapeutic alliance would be the first link in the chain of therapeutic adherence. The doctor-patient therapeutic relationship is the environment where the rest of the therapeutic instruments, pharmacological or not, is housed. Each type of doctor-patient relationship involves a different relationship with pharmacological treatment; but also, the doctor-drug union style imposes a doctor-patient relationship. In any case, the discontinuity of the treatment indicates in some way a discontinuity of the doctor-patient relationship.

To increase therapeutic adherence, it is necessary to start with a self-reflection on what theoretical framework the doctor has in relation to the role of drugs in health care, and the instruction and preparation of the health professional to develop persuasive, affective and effective communications; simplify therapeutic regimens (doses, schedules), as well as schedule the frequency of patient visits, the application of selective reinforcements of health behaviors and behavioral contracts.

\section{References}

1. World Health Organization (2003) Adherence to long-term therapies: Evidence for action. World Health Organization, Geneva, Switzerland.

2. Niolu C, Siracusano A (2005) Discontinuità psicofarmacologica e aderenza. Roma: Il Pensiero Scientifico Editore.

3. Dilla T, Valladares A, Lizán L, Sacristán JA (2009) Treatment adherence and persistence: Causes, consequences and improvement strategies. Aten Primaria 41(6): 342-348.

4. Martín Alfonso L (2004) Acerca del concepto de adherencia terapéutica. Rev Cubana Salud Pública 30(4): 350-352.

5. Zarragoitia Alonso I (2010) Therapeutic adherence on depression. Rev Hosp Psiquiátrico de la Habana 7(3).

6. Turabián JL, Perez Franco B (2011) Impact of the induced prescription on the doctor-patient relationship. Rev Calid Asist 26(1): 67-69.

7. Turabián JL, Moreno Ruiz SM (2016) The fable of the pine and the palm tree: the two extremes. Strategies to maximize the placebo effect and minimize the nocebo effect in primary health care. Ment Health Addict Res 1.

8. Turabián JL, Perez Franco B (2011) Non-pharmacological aspects of medications. Semergen 37(5): 246-251.

9. Gutiérrez Islas E, Báez Montiel BB, Turabián JL, BolañosMM, Ontañón HJR, et al. (2012) Patients with adverse drug reactions have a higher prevalence of emotional disorders. Aten Primaria 44: 720-726.

10. American Medical Association (2000) Doctor-patient relationship: The doctor-patient relationship in pharmacotherapy: improving treatment effectiveness. JAMA 284(21): 2793-2794.

11. Garjón FJ (2009) Prescribing drugs to patients receiving out-patient care. Anales Sis San Navarra 32(1):

12. Turabián JL, Pérez Franco B (2008) The Effect of seeing the sea for the first time. An attempt at defining the family medicine law: the interview is clinical medicine. Aten Primaria 40(11): 565-566.

13. Rolland JS (1994) Families, illness, and disability. An integrative treatment model. Bassic Books, New York, USA.

14. Turabián JL (2017) A narrative review of natural history of diseases and continuity of care in family medicine. Arch Community Med Public Health 3(1): 041-047. 
15. Martínez Hernández D, González Núñez J (2017) Investigación de la Adherencia terapéutica en el paciente en prevención secundaria. Sefyp, Mexico, USA.

16. Turabián JL, Pérez Franco B (2001) Actividades Comunitarias en Medicina de Familia y Atención Primaria [Community Activities in Family Medicine and Primary Care]. Madrid: Díaz de Santos pp.1-16.

17. Balint M, Hunt J, Joyce D, Marinker M, Woodcock J (1984) Treatment or diagnosis. A study of repeat prescriptions in general practice, Tavistock Publications, London, UK.

18. Turabián Fernández JL, Pérez Franco B (2010) The concept of treatment in familiy medicine: A contextualised and contextual map of a city hardly seen. Aten Primaria 42(5): 253-254.

19. Simons RC (1984) Understanding human behavior in health and illness. Baltimore, Williams \& Wilkins, Philadelphia, Pennsylvania, USA.

20. González Menéndez R (1979) Psicología para médicos generales. Ciudad de La Habana, Cuba: Editorial Científico-Técnica.

21. Turabián JL (2017) Physician-patient relationship in obstetrics and gynecology. Gynecol Obstet 7: e123.

22. Núñez de Villavicencio F, González Menéndez R (2001) In: Núñez de Villavicencio F (Eds.), Psicología y Salud, Ciudad de la Habana: ECIMED.

23. Moreira V (2012) From person-centered to humanisticphenomenological psychotherapy: The contribution of merleau-ponty to carl rogers's thought. Person-Centered \& Experiential Psychotherapies 11(1): 48-63.

24. Turabián JL, Perez Franco B (1998) Which is the goal of health education and community activities in primary care? Aten Primaria 22(10): 662666.
25. Lucassen P, Olesen F (2016) Context as a drug: Some consequences of placebo research for primary care. Scand J Prim Health Care 34(4): 428433.

26. Leigh H, Reiser MF (1992) The patient. Biological, psychological, and social dimensions of medical practice, Plenun Medical Book Company, New York, USA.

27. Turabián JL (2018) Contextual treatment: A conceptualization and systematization from general medicine. Int J Fam Commun Med 2(3): 137-144.

28. Hammersley D (1995) Counselling people on prescribed drugs, Sage Publications, London, UK.

29. Wald NJ, Law MR (2003) A strategy to reduce cardiovascular disease by more than $80 \%$. BMJ 326(7404): 1419.

30. Tanne JH (2007) NEJM sees promise in polypill for low and middle income countries. BMJ 334: 172 .

31. Turabián JL (2018) The wrong transformation of doctor-patient relationship in drug-patient relationship: From the doctor himself as a drug to doctor as drug dealer. Chronicle of Medicine and Surgery 3(1): 298-301.

32. OMS (2003) El incumplimiento del tratamiento prescrito para las enfermedades crónicas es un problema mundial de gran envergadura.

33. Turabián JL, Jove RC, Rodriguez LEM, Almonte FER, Ruiz SM, et al. (2016) Epidemiology of companions of the patients in family medicine. Making the invisible visible. Health Edu Care 1(2): 37-40.

34. Turabián JL, Rodriguez LEM, Ruiz SM, Almonte FER, Jove RC, et al. (2016) Types of companion of the patient in family medicine. J Health Edu Res Dev 4: 186.
Creative Commons Attribution 4.0 International License

For possible submissions Click Here

\section{Submit Article}

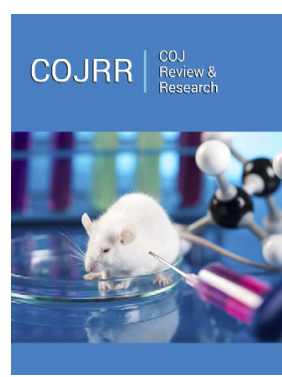

COJ Reviews \& Research

\section{Benefits of Publishing with us}

- High-level peer review and editorial services

- Freely accessible online immediately upon publication

- Authors retain the copyright to their work

- Licensing it under a Creative Commons license

- Visibility through different online platforms 